\title{
‥
}

RESEARCH AND EDUCATION

\section{Effect of crosslinkers on bond strength stability of fiber posts to root canal dentin and in situ proteolytic activity}

\author{
Juliana R. L. Alonso, DDS, MS, ${ }^{a}$ Fernanda G. Basso, DDS, MS, PhD, ${ }^{b}$ Débora L. S. Scheffel, DDS, MS, PhD, \\ Carlos Alberto de-Souza-Costa, DDS, MS, PhD, and Josimeri Hebling, DDS, MS, PhD
}

The major cause of adhesive failures is the degradation of the hybrid layer, ${ }^{1}$ a biocompound formed by the entanglement of resin monomers and dentin proteins, mainly collagen. ${ }^{2-5}$ This layer is responsible for the mechanical retention of the resin material and for sealing dentin. ${ }^{2}$ However, the presence of water permeating the hybrid layer and the action of dentin proteases degrading the collagen compromise the long-term stability of the resin-dentin bond. . $^{6-10}$

Dentin is composed of approximately $45 \%$ mineral content by volume, $33 \%$ organic content (mostly type I collagen), and $22 \%$ water. ${ }^{11}$ After etching, nearly $10 \mu \mathrm{m}$ of the surface of the dentin is demineralized. The composition of the etched dentin zone then becomes, by volume, $33 \%$ organic content and $67 \%$ water. ${ }^{12}$ The presence of water at this point of the bonding procedure is important from the control group.

\begin{abstract}
Statement of problem. Improved stability of the adhesive interface can be obtained using crosslinkers. However, research on the use of crosslinkers in root dentin is lacking.

Purpose. The purpose of this in vitro study was to evaluate the effect of crosslinkers on the proteolytic activity of root dentin and on the bond strength of resin-cemented fiber posts.

Material and methods. Single root canals were obtained from premolars $(n=48)$ and endodontically treated before being divided into 4 groups: deionized water (control), $0.5 \mathrm{~mol} / \mathrm{L}$ carbodiimide, $5 \%$ proanthocyanidin, or $5 \%$ glutaraldehyde. After removing the canal sealer, the dentin was etched with phosphoric acid, followed by water rinsing and the application of the crosslinkers for 60 seconds. Fiber posts were cemented using an adhesive (Single Bond 2) and resin cement (RelyX ARC). The roots were then transversally sectioned to obtain $1 \mathrm{~mm}$ thick specimens from the cervical, middle, and apical thirds and then aged for 24 hours or 9 months. Nine roots per group were used for the push-out test and 3 for determining the proteolytic activity of the root dentin by in situ zymography. Bond strength data were submitted to a mixed-model ANOVA and Bonferroni tests $(\alpha=.05)$.
\end{abstract}

Results. Only proanthocyanidin negatively affected the 24-hour bond strength. After 9 months, a significant decrease in bond strength was seen for all groups, except for the crosslinked treated specimens from the cervical third of the root canal. Intense gelatinolytic activity was detected in the control group after 24 hours but was inhibited in the crosslinker-treated groups. Proteolytic activity was also not detected after 9 months for the groups treated with the crosslinkers, irrespective of the root canal third. Conversely, proteolytic activity increased for the specimens

Conclusions. Although no proteolytic activity was detected in the hybrid layers along the entire root canal, dentin biomodification with crosslinkers was effective in preventing bond strength loss only in the cervical third. (J Prosthet Dent 2018;119:494.e1-e9)

to prevent the approximation of collagen molecules, which would lead to the establishment of new hydrogen bonds between adjacent peptide chains, resulting in

\footnotetext{
Support by the Brazilian research funding agencies São Paulo Research Foundation (FAPESP 2014/10183-8) and the National Council for Scientific and Technological Development (CNPq 307695/2014-6).

${ }^{a}$ Assistant researcher, Department of Oral Rehabilitation, São Paulo State University (UNESP), School of Dentistry, São Paulo, Brazil.

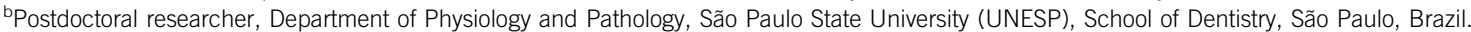

${ }^{c}$ Postdoctoral researcher, Department of Pediatric Dentistry and Orthodontics, São Paulo State University (UNESP), School of Dentistry, São Paulo, Brazil.

dProfessor, Department of Physiology and Pathology, São Paulo State University (UNESP), School of Dentistry, São Paulo, Brazil.

eProfessor, Department of Pediatric Dentistry and Orthodontics, São Paulo State University (UNESP), School of Dentistry, São Paulo, Brazil.
} 


\section{Clinical Implications}

Determining whether dentin biomodification with crosslinkers interferes with the bond strength of fiber posts cemented to root canal dentin and protects hybrid layers from degradation is essential before considering their clinical use. The stabilization of bond strengths and the inhibition of dentin proteases promoted by these crosslinkers could increase the longevity of prosthetic procedures that use resin adhesion to root dentin.

collagen network shrinkage. ${ }^{13}$ Maintenance of an expanded collagen network is imperative to keep the interfibrilar spaces for the adhesive system infiltration and formation of the hybrid layer. ${ }^{13,14}$ Conversely, excessive water at the moment of monomeric infiltration facilitates the separation of hydrophilic and hydrophobic monomers $^{15,16}$ and negatively influences monomeric conversion, ${ }^{17}$ contributing to the formation of imperfect hybrid layers. ${ }^{15,18}$ Moreover, the presence of water enables the activity of dentin endopeptidases such as matrix metalloproteinases (MMPs) and cysteine cathepsins, which break down collagen by adding a water molecule to the polypeptide chain (hydrolases). ${ }^{6,8}$ MMP-2, - -3, -9, -8 , and -20 are found in sound, mineralized dentin. ${ }^{19-21}$

The durability of the hybrid layer depends on the intrinsic resistance of its constituents to the degradation processes. ${ }^{22}$ While the resin component is susceptible to the esterase-catalyzed hydrolysis, ${ }^{23}$ collagen is susceptible to both hydrolytic and protease-mediated degradation. ${ }^{24,25}$ Some natural and synthetic agents have been used to increase the number of crosslinks that occur naturally within and between collagen molecules and fibrils (endogenous crosslinks). The new exogenous crosslinks make the collagen more resistant to degradation. ${ }^{26-34}$ The most investigated crosslinkers are carbodiimide (1-ethyl-3-[3-dimethylaminopropyl] carbodiimide hydrochloride; EDC), proanthocyanidin (PA), and glutaraldehyde (GD). ${ }^{29,30,35,36}$ In addition to increasing the number of collagen crosslinks, these agents are MMPs and cysteine cathepsins nonspecific inhibitors. ${ }^{34,37-39}$ Thus, hybrid layers produced in the presence of crosslinkers are more resistant to degradation and more stable over time. ${ }^{26-34}$

The effects of crosslinkers have been studied on interfaces produced with coronal dentin, ${ }^{35,36}$ with little information available about the performance of these agents on hybrid layers formed with the root canal dentin. ${ }^{40-42}$ Unfavorable conditions at the time of the establishment of the resin-root dentin bond include the use of chemical agents during endodontic treatment, ${ }^{41}$ high cavity configuration factor ( $\mathrm{C}$ factor) of the root canal, difficulties in adequately evaporating solvents, limited access of light in the deeper portions of the canal to proper polymerization of the resin material, and contamination of the dentin walls by root canal filling material. ${ }^{43}$

Coronary and radicular dentin differ as to the presence and concentration of MMP-2, -9 , and $-13^{44,45}$ and have different mechanical properties, such as lower hardness and elastic modulus. ${ }^{46}$ Therefore, investigating whether the positive effects obtained when crosslinkers are used in the coronal dentin adhesion process are also seen in bonding to root canal dentin is important. Thus, the null hypotheses tested were that the biomodification of the root canal dentin with crosslinkers has no effect on the immediate bond strength of fiber posts cemented with a resin-based luting material, on the proteolytic activity of the dentin, and on the stability of the hybrid layers after aging.

\section{MATERIAL AND METHODS}

Forty-eight roots of single-rooted human premolars were obtained after approval by the institutional review board of the Araraquara Dental School (FOAr)-UNESP (CAAE, 34373314.6.0000.5416). Thirty-six roots were selected for push-out testing and 12 for in situ zymography.

The canals were prepared by 1 trained operator (J.R.L.A.) using the step-back technique up to file number 35K (Dentsply Sirona), followed by irrigation with 5 $\mathrm{mL}$ of $2.5 \% \mathrm{NaOCl}$. The canal was then dried with paper cones and irrigated with 17\% ethylenediaminetetraacetic acid (EDTA) for 3 minutes under agitation, followed by neutralization, suction, and drying. At the end of the chemical-mechanical preparation, the canal was filled with gutta percha with endodontic sealer (AH Plus; Dentsply Sirona). The teeth were stored for 1 month in $100 \%$ humidity at $37^{\circ} \mathrm{C}$. The gutta percha was removed with Gates-Glidden burs (Dentsply Sirona) to a depth of at least $8 \mathrm{~mm}$. Glass fiber posts (FGM Dental Products) were disinfected with ethanol ( $99.8 \mathrm{vol} \%$ ) for 60 seconds and then thoroughly air dried before the application of a silane (RelyX ARC Primer; 3M ESPE).

Before bonding, the root canal dentin was etched with 35\% phosphoric acid (Ultra Etch; Ultradent Products, Inc) for 15 seconds, followed by rinsing with deionized water for 20 seconds. Excess water was removed with paper points, keeping the dentin surface moist. The etched root dentin was treated for $60 \mathrm{sec}-$ onds with deionized water (control); $0.5 \mathrm{~mol} / \mathrm{L}$ EDC solution (Sigma-Aldrich Corp); 5\% PA solution (0.0084 $\mathrm{mol} / \mathrm{L}$, Vitis vinifera; Shaanxi Sinuoti Biotech Co Ltd), or 5\% GD solution (0.0499 mol/L; Sigma-Aldrich Corp). After 60 seconds, the canal was rinsed for 10 seconds and dried with paper points. The adhesive (Single Bond 2; 3M ESPE) was applied in 2 consecutive layers, 

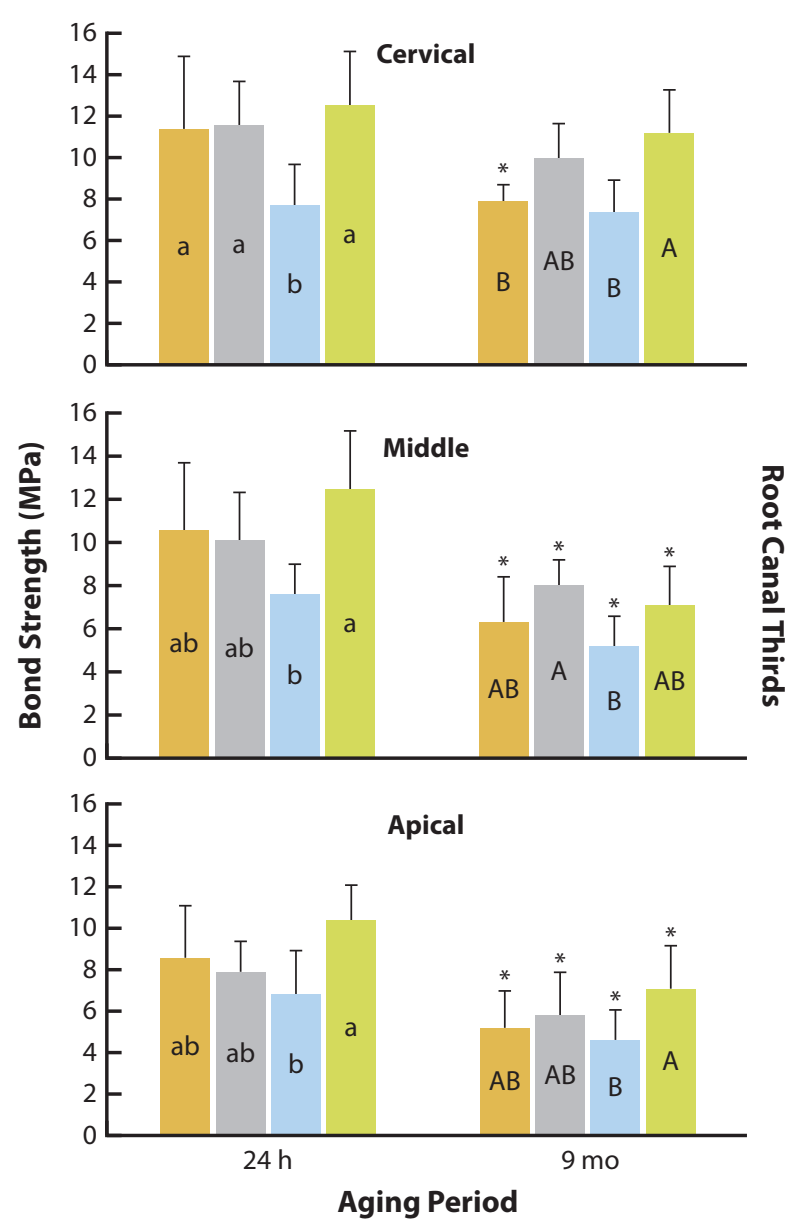

$\square$ Deionized water $\square 0.5 \mathrm{~mol} / \mathrm{L} \mathrm{EDC} \backsim 5 \% \mathrm{PA} \backsim 5 \% \mathrm{GD}$

Figure 1. Bond strength (MPa) of fiber posts bonded to root canal dentin obtained by push-out test. Groups identified by same lowercase or uppercase letter not statistically different $(P>.05)$. *Nine-month aging groups statistically different from respective group at 24 hours $(P<.05)$.

followed by solvent evaporation with a mild blast of air. The adhesive system was light activated for 20 seconds with a light-emitting diode unit (Radii Plus; SDI Ltd) emitting an irradiance of $1000 \mathrm{~mW} / \mathrm{cm}^{2}$. After application of the adhesive, resin cement (RelyX ARC; 3M ESPE) was inserted into the canal with a dental explorer. The resin cement was also applied to the surface of the post before it was inserted into the root canal. The cement was light activated for 40 seconds with the light tip placed at $1 \mathrm{~mm}$ from the cervical end of the root.

After 24 -hour storage at $37^{\circ} \mathrm{C}$ and $100 \%$ humidity, the roots were transversely cut into $1 \mathrm{~mm}$ thick disks with a diamond blade coupled to a metallographic saw (ISOMET 1000; Buehler). Two disks were obtained from each cervical, middle, and apical third of the root. One disk from each third was used for the immediate tests, and the remaining disks were stored immersed in artificial saliva solution (50 mM HEPES; $25 \mathrm{mM}$ $\mathrm{CaCl}_{2} \cdot 2 \mathrm{H}_{2} \mathrm{O} ; 0.2 \mathrm{mM}$ zinc chloride; $\mathrm{pH} 7.4$ ) for 9 months.

The push-out test was performed in a universal testing machine (DL-Digital Line; EMIC Ltd) equipped with a $200 \mathrm{~N}$ load cell operating at the speed of $1.0 \mathrm{~mm} /$ min. The dentin disks were placed in the machine in such a way that the wider surface of the disk remained facing downward. A metal tip attached to the testing machine was positioned in the central portion of the dentin disk and in contact with the glass fiber post; therefore, it could be freely moved without touching the walls of the root canal. The movements were initiated by means of a computer program (Tesc-Script Test; EMIC Ltd) until the specimen was completely extruded. Bond strength (in $\mathrm{MPa}$ ) was calculated by dividing the extrusion load $(\mathrm{N})$ by the total area $(\mathrm{A})$ of the cemented post: $A=\pi(r 1+r 2) \sqrt{ }(r 1-r 2) 2+2 h$, where $r 1$ is the larger radius, $\mathrm{r} 2$ is the smaller radius, and $\mathrm{h}$ is the specimen height.

The specimens were evaluated in a stereomicroscope (Mod SZX7; Olympus Corp) to determine the type of fracture in magnifications from $\times 10$ to $\times 30$. The fractures were classified into 5 groups: adhesive between post and resin cement (without visible cement around the post); mixed with resin cement covering up to $50 \%$ of the circumference of the post; mixed with resin cement covering more than $50 \%$ of the circumference of the post; adhesive between resin luting cement and dentin (post completely covered with resin cement); or cohesive in dentin. ${ }^{41}$

To detect protease activity in the hybrid layer and root canal dentin, a protocol based on Mazzoni et $\mathrm{al}^{10}$ was used. Each disk was bonded to acrylic blades with cyanoacrylate resin (Henkel Ltd), taking care to avoid blisters between the disk and the acrylic resin surface. The specimens were then reduced with 1200- and 4000grit silicon carbide abrasive papers until the final thickness was $0.3 \mathrm{~mm}$ and stored in deionized water at $4^{\circ} \mathrm{C}$ for 24 hours. The technique of in situ zymography was performed using a gelatinase/collagenase assay kit (EnzChek; Thermo Fisher Scientific). Fifty microliters of gelatinous solution containing fluorescein was applied on the dentin disks, which were covered by a glass coverslip and stored in the dark in an incubator at $37^{\circ} \mathrm{C}$ in $100 \%$ humidity. As a control reaction, a group treated with the gellike solution but without fluorescein was tested. The specimens were analyzed under a fluorescence microscope (DM 5500; Leica Microsystems), with excitation $498 \mathrm{~nm}$ and emission $530 \mathrm{~nm}$, after 24 hours of incubation. Images were obtained using a fluorescence microscope green channel, with $\times 20$ increase (objective lens) and a gain of 1.1. The images were analyzed with ImageJ software (National Institutes of Health) with an 8-bit 
Table 1. Distribution of failure mode for specimens obtained from cervical third of root canal aged for 24 hours or 9 months in artificial saliva

\begin{tabular}{|c|c|c|c|c|c|c|}
\hline \multirow[b]{2}{*}{ Aging Period } & \multirow[b]{2}{*}{ CrossLinker } & \multicolumn{5}{|c|}{ Failure Mode } \\
\hline & & $\begin{array}{l}\text { Adhesive Between } \\
\text { Post and Cement }\end{array}$ & $\begin{array}{c}\text { Mixed (Up to } 50 \% \\
\text { Cement-Covered Post) }\end{array}$ & $\begin{array}{l}\text { Mixed (More Than } \\
50 \% \text { Covered Post) }\end{array}$ & $\begin{array}{l}\text { Adhesive Between } \\
\text { Cement and Dentin }\end{array}$ & Cohesive in Dentin \\
\hline \multirow[t]{5}{*}{$24 \mathrm{~h}$} & Deionized water & $3(37.5 \%)$ & 1 (12.5\%) & $2(25.0 \%)$ & $2(25.0 \%)$ & 0 \\
\hline & $0.5 \mathrm{~mol} / \mathrm{L} \mathrm{EDC}$ & $6(85.7 \%)$ & 0 & 0 & $1(14.3 \%)$ & 0 \\
\hline & $5 \%$ PA & 0 & 1 (11.1\%) & 2 (22.2\%) & $6(66.7 \%)$ & 0 \\
\hline & $5 \%$ GD & 7 (77.8\%) & 0 & 0 & $2(33.3 \%)$ & 0 \\
\hline & Total count & 16 (48.5\%) & $2(6.1 \%)$ & 4 (12.1\%) & 11 (33.3\%) & 0 \\
\hline \multirow[t]{5}{*}{$9 \mathrm{mo}$} & Deionized water & $4(44.4 \%)$ & $1(11.1 \%)$ & $2(22.2 \%)$ & $2(22.2 \%)$ & 0 \\
\hline & $0.5 \mathrm{~mol} / \mathrm{L} \mathrm{EDC}$ & $6(75.0 \%)$ & $1(12.5 \%)$ & 0 & 0 & $1(12.5 \%)$ \\
\hline & $5 \%$ PA & $2(22.2 \%)$ & $3(33.3 \%)$ & $2(22.2 \%)$ & $2(22.2 \%)$ & 0 \\
\hline & $5 \% \mathrm{GD}$ & $2(22.2 \%)$ & $5(55.6 \%)$ & $1(11.1 \%)$ & $1(11.1 \%)$ & 0 \\
\hline & Total count & $14(40.0 \%)$ & $10(28.6 \%)$ & 5 (14.3\%) & $5(14.3 \%)$ & $1(2.9 \%)$ \\
\hline
\end{tabular}

Data presented as count (\% within crosslinker). EDC, carbodiimide; PA, proanthocyanidin; GD, glutaraldehyde.

Table 2. Compilation of failure mode distribution for middle and apical thirds of root canal in specimens aged in artificial saliva for 24 hours and 9 months

\begin{tabular}{|c|c|c|c|c|c|c|}
\hline \multirow[b]{2}{*}{ Aging Period } & \multirow[b]{2}{*}{ CrossLinker } & \multicolumn{5}{|c|}{ Failure Mode } \\
\hline & & $\begin{array}{l}\text { Adhesive Between } \\
\text { Post and Cement }\end{array}$ & $\begin{array}{l}\text { Mixed (Up To 50\% } \\
\text { Cement-Covered Post) }\end{array}$ & $\begin{array}{l}\text { Mixed (More Than } 50 \% \\
\text { Covered Post) }\end{array}$ & $\begin{array}{l}\text { Adhesive Between } \\
\text { Cement and Dentin }\end{array}$ & Cohesive in Dentin \\
\hline \multirow[t]{5}{*}{$24 \mathrm{~h}$} & Deionized water & $8(47.1 \%)$ & 0 & $3(17.6 \%)$ & $5(29.4 \%)$ & $1(5.9 \%)$ \\
\hline & $0.5 \mathrm{~mol} / \mathrm{L} \mathrm{EDC}$ & $10(58.8 \%)$ & $2(11.8 \%)$ & $3(17.6 \%)$ & $1(5.9 \%)$ & $1(5.9 \%)$ \\
\hline & $5 \%$ PA & $3(16.7 \%)$ & $3(16.7 \%)$ & $4(22.2 \%)$ & 7 (38.9\%) & $1(5.6 \%)$ \\
\hline & $5 \%$ GD & 8 (47.1\%) & $2(11.8 \%)$ & $3(17.6 \%)$ & $3(17.6 \%)$ & 0 \\
\hline & Total count & 29 (42.6\%) & 7 (10.3\%) & $13(19.1 \%)$ & $16(23.5 \%)$ & $3(4.3 \%)$ \\
\hline \multirow{5}{*}{$9 \mathrm{mo}$} & Deionized water & $5(27.8 \%)$ & $2(11.1 \%)$ & $4(22.2 \%)$ & 6 (33.3\%) & $1(5.6 \%)$ \\
\hline & $0.5 \mathrm{~mol} / \mathrm{L}$ EDC & $9(50.0 \%)$ & $4(22.2 \%)$ & $3(16.7 \%)$ & $1(5.6 \%)$ & $1(5.6 \%)$ \\
\hline & $5 \%$ PA & $6(33.3 \%)$ & 0 & $5(27.8 \%)$ & $6(33.3 \%)$ & $1(5.6 \%)$ \\
\hline & $5 \% \mathrm{GD}$ & 12 (70.6\%) & 0 & 0 & $5(29.4 \%)$ & 0 \\
\hline & Total count & 32 (45.1\%) & $6(8.6 \%)$ & 12 (16.9\%) & $18(25.4 \%)$ & $3(4.2 \%)$ \\
\hline
\end{tabular}

Data are presented as count (\% within crosslinker). EDC, carbodiimide; PA, proanthocyanidin; GD, glutaraldehyde.

grayscale, 34 to 200 contrast, and a threshold value of 28 to 30 . The presence of fluorescence was indicative of proteolytic degradation.

Bond strength data were submitted to 3-way mixed ANOVA with 1 between-group factor (crosslinker) and 2 repeated-measures factors (root canal third and aging period), complemented by the Bonferroni multiple comparisons test. The possible association between the dentin treatment and the mode of failure was analyzed by Fisher exact tests ( $\alpha=.05$ for all tests).

\section{RESULTS}

The bond strength values (immediately [ 24 hours] and after 9 months of aging) for the different thirds of the root canal dentin, as a function of the crosslinkers, are shown in Figure 1. All 2-way interactions (Crosslinker $\times$ Aging period, $P<.001$; Crosslinker $\times$ Root canal third, $P<.001$; and Aging period $\times$ Root canal third, $P=.003$ ) and the 3 -way interaction (Crosslinkers $\times$ Root canal third $\times$ Aging period, $P=.045$ ) exerted a significant effect on bond strength. Overall, bond strength values to cervical root canal dentin were statistically higher $(P<.001)$ than bond strength values to apical root canal dentin, except for PA groups, at 24 hours of aging (Fig. 1). For specimens treated with PA, no statistical differences $(P>.05)$ were noted among the 3 radicular thirds.

For the cervical third after 24 hours of aging, all groups had bond strength values statistically similar $(P>.05)$ to those of the control group, except for PA, where significantly lower bond strengths $(P<.05)$ were observed when PA was compared with EDC and GD (Fig. 1). As for the middle and apical thirds of the root canal, similar results were seen. The mean bond strengths of PA and GD were statistically similar to those of the controls $(P>.05)$, but a significant difference $(P<.05)$ was detected between these 2 crosslinkers (Fig. 1). After 9 months of aging, crosslinkers exerted a protective effect against degradation of the hybrid layer only for the cervical third of the root canal. Significant reduction in bond strength was observed in the control group, while bond strengths did not differ from the values obtained after 24 hours for all crosslinker groups. 

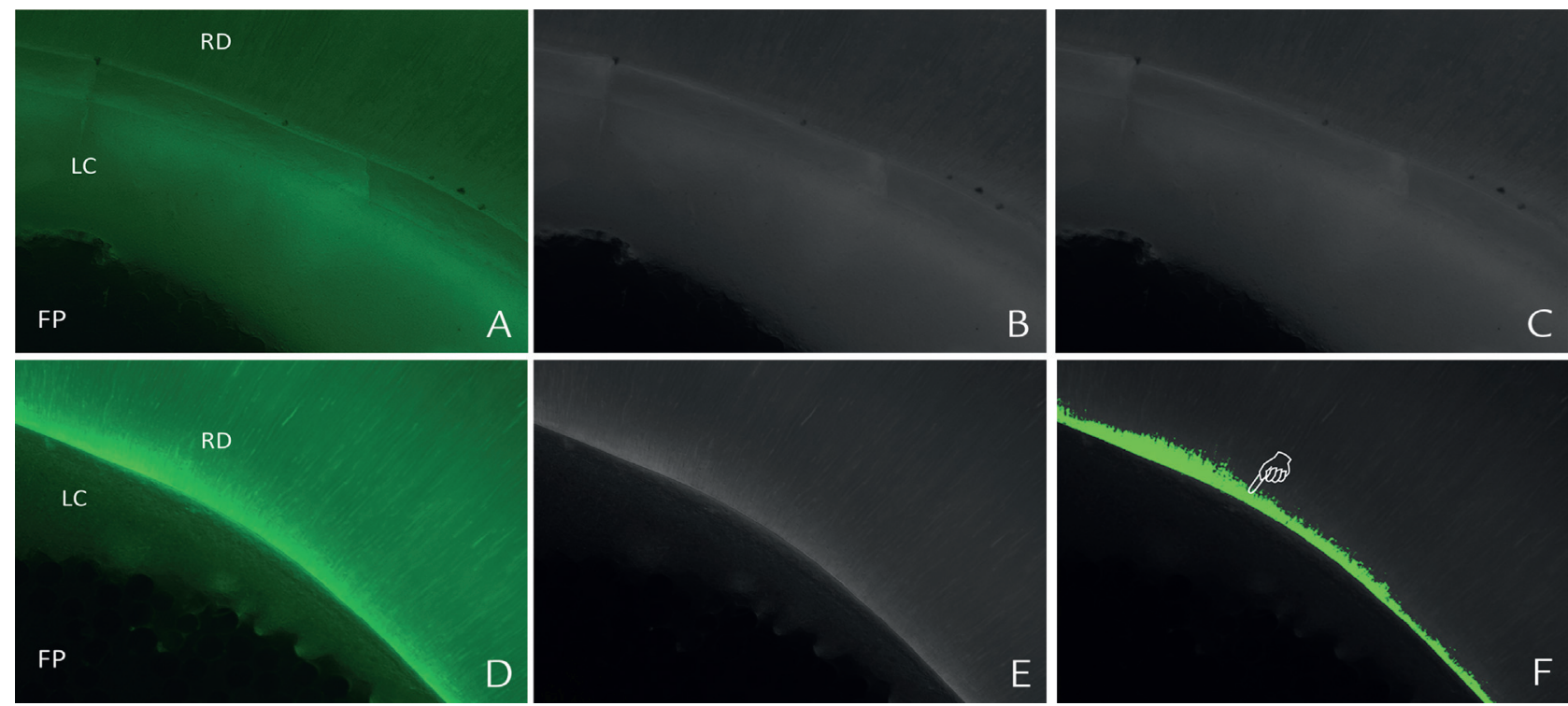

Figure 2. Fluorescence microscope images from control group (deionized water) (original magnification, $\times 20$ ). A-C, No fluorescein added to gelatinous solution applied over specimen; therefore, no proteolytic activity seen. D-F, Fluorescein incorporated into gelatinous solution. As activated proteases degrade gelatin, emitted fluorescence is captured by microscope. F, Intense proteolytic activity seen in hybrid layer (bright green) (pointer). FP, fiber post; LC, luting cement; RD, root dentin.

Conversely, a significant reduction $(P<.05)$ in bond strength was found after 9 months of storage in artificial saliva, irrespective of the dentin treatment, for all specimens from the middle and apical thirds of the root canal (Fig. 1).

A significant association between the type of treatment and the mode of failure was found only for the cervical third of the root canal at the 24-hour aging period (Fisher exact test $=17.945 ; P=.005$ ) (Table 1 ). At the 24-hour aging period, the percentage of failures increased between the fiber post and the luting cement after the use of EDC and GD, while after the use of PA, the percentage of failures increased between the luting cement and the dentin. For the PA crosslinker, a shift was noted from predominantly adhesive failures between the luting cement and the dentin after 24 hours of aging to mixed failures after 9 months. A shift in the distribution of failure type was also seen for GD. While adhesive failures between the fiber post and the luting cement were predominant at the 24-hour aging period, after 9 months of aging, mixed failures predominated. A compilation of failure type for the middle and apical thirds of the root canal is shown in Table 2.

Validation of the in situ zymography is shown in Figure 2. After aging for 24 hours, specimens from the control group showed intense fluorescence in the hybrid layer for all 3 root canal thirds (Fig. 3A-C). In contrast, no fluorescence in the hybrid layer was detected in specimens treated with EDC (Fig. 3D-F), PA (Fig. 3G-I), or GD (Fig. 3J-L). After 9 months of aging, fluorescence was also not seen in the specimens treated with the crosslinkers, while gelatinolytic activity was detected in all specimens from the control group (Fig. 4).

\section{DISCUSSION}

The immediate bond strength of fiber posts cemented to root canal dentin with a resin-based luting material was negatively affected by the application of PA, while the performance of EDC and GD after 24 hours of aging was similar to that of the control where the traditional wetbonding technique using only water was performed. Therefore, the first null hypothesis, no difference for any group, was rejected. The $5 \%$ PA solution had a dark brown color, and undissolved particles could be seen in the final solution. Even after rinsing the PA solution after the 60 seconds of application, the dentin remained brownish. The pigmentation of dentin is a disadvantage of PA that could limit its clinical use, especially in anterior restorations. Because PA residues on the dentin could adversely influence bond strength, filtering the PA solution has been suggested. ${ }^{35,41}$ Cecchin et $\mathrm{al}^{41}$ also evaluated the effect of grape-seed extract, which is rich in PA, on bond strength between fiber posts and root dentin. However, the authors used higher concentrations of PA $(6.5 \%$ and $10 \%)$ and a much longer application time of 5 minutes. Nevertheless, loss of bond strength was seen after 12 months of aging when the $10 \%$ solution was used.

In specimens treated with PA most immediate failures between cement and dentin were adhesive, while for EDC and GD most failures occurred between the fiber post and the cement (Table 1). An adhesive failure 

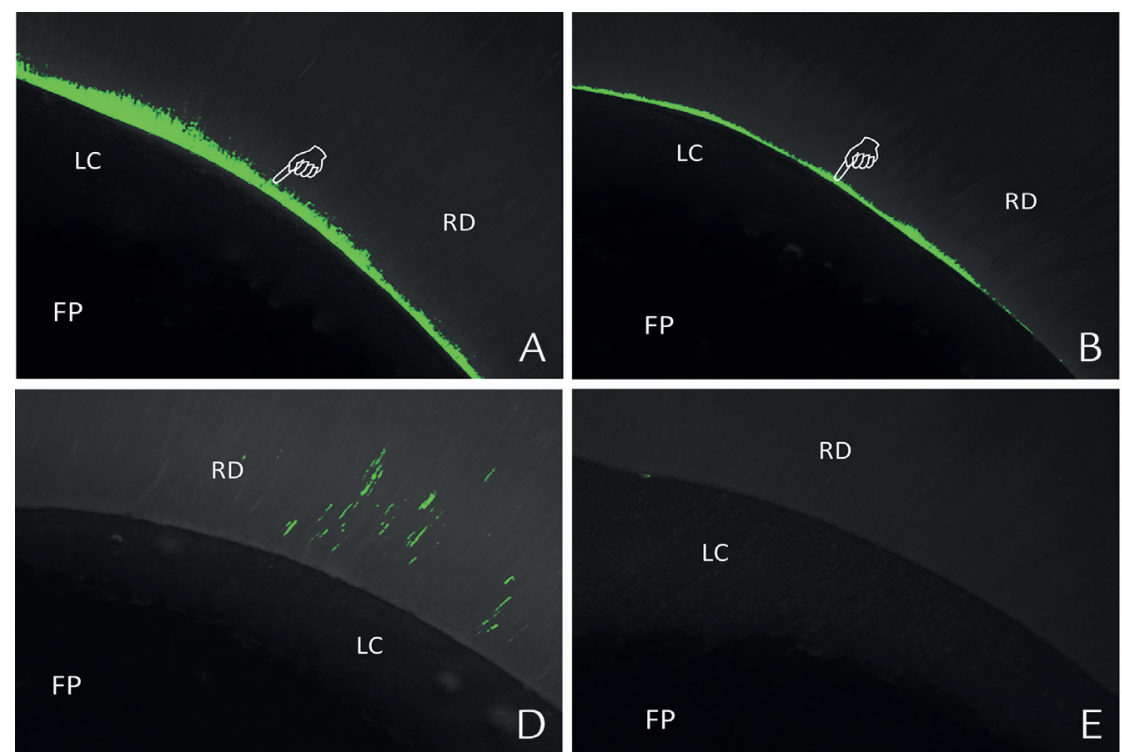

RD

LC

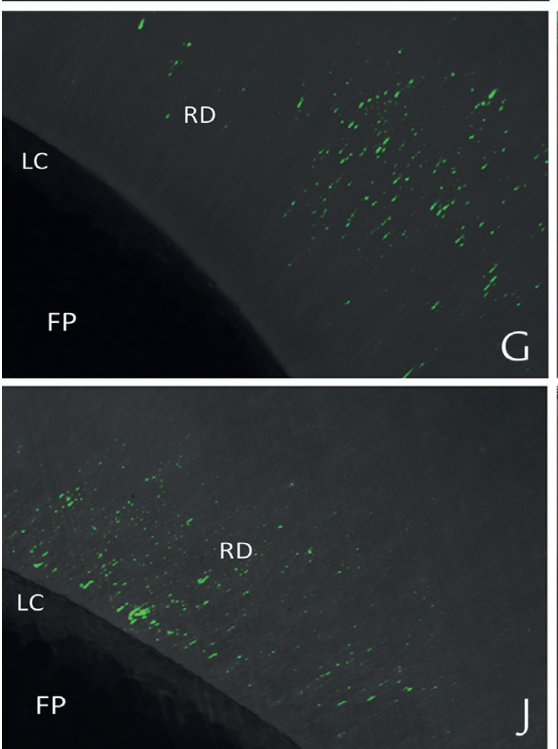

FP

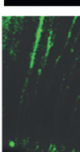

LC

FP
RD
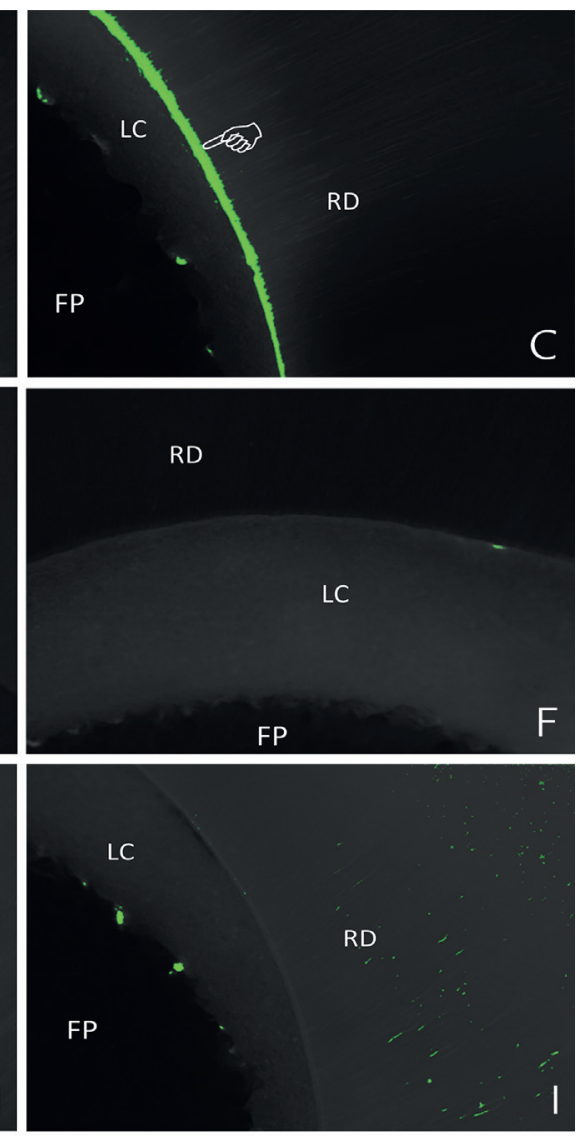

LC

RD

FP

Figure 3. Fluorescence microscope images from 24 hours (original magnification, $\times 20$ ). A-C, Intense fluorescence seen in hybrid layers (pointer, bright green) from control group (deionized water). No fluorescence within hybrid layers, irrespective of root canal third. D-F, EDC-treated specimens. G-I, PA-treated specimens. J-L, GD-treated specimens. Fluorescence seen along dentinal tubules corresponds to gelatinolytic activity in lamina limitans, delicate layer of connective tissue that overlays dentinal tubules internally. EDC, carbodiimide; FP, fiber post; GD, glutaraldehyde; LC, luting cement; PA, proanthocyanidin; RD, root dentin.

pattern indicates reduced bonding and suggests that PA residues might have interfered with the bond. However, specimens treated with 5\% PA had significantly reduced proteolytic activity.

The same protease inactivation effect was also seen for $5 \%$ GD and $0.5 \mathrm{~mol} / \mathrm{L} \mathrm{EDC} \mathrm{(Fig.} \mathrm{3).} \mathrm{Therefore,} \mathrm{the}$ second null hypothesis was rejected. Shafiei et $\mathrm{al}^{40}$ also demonstrated no interference of EDC on the immediate bond strength values of all the resin cements investigated. The authors applied EDC at a concentration of $0.3 \mathrm{~mol} / \mathrm{L}$ for 60 seconds. In the present study, a clinically feasible time of application was also investigated, and all crosslinkers were therefore kept passively in contact with the dentin for 60 seconds before rinsing. ${ }^{32,38-40}$

The results of in situ zymography demonstrated a significant reduction in the proteolytic activity of root dentin, which was virtually absent up to 9 months after the application of the crosslinkers. Similar results have been reported for coronal dentin with the same application time of 60 seconds. ${ }^{32,33,38,39}$ Additionally, EDC in the same concentration used in this study, applied for 30 or 60 seconds, led to the increased modulus of elasticity of dentin collagen. ${ }^{47}$ 

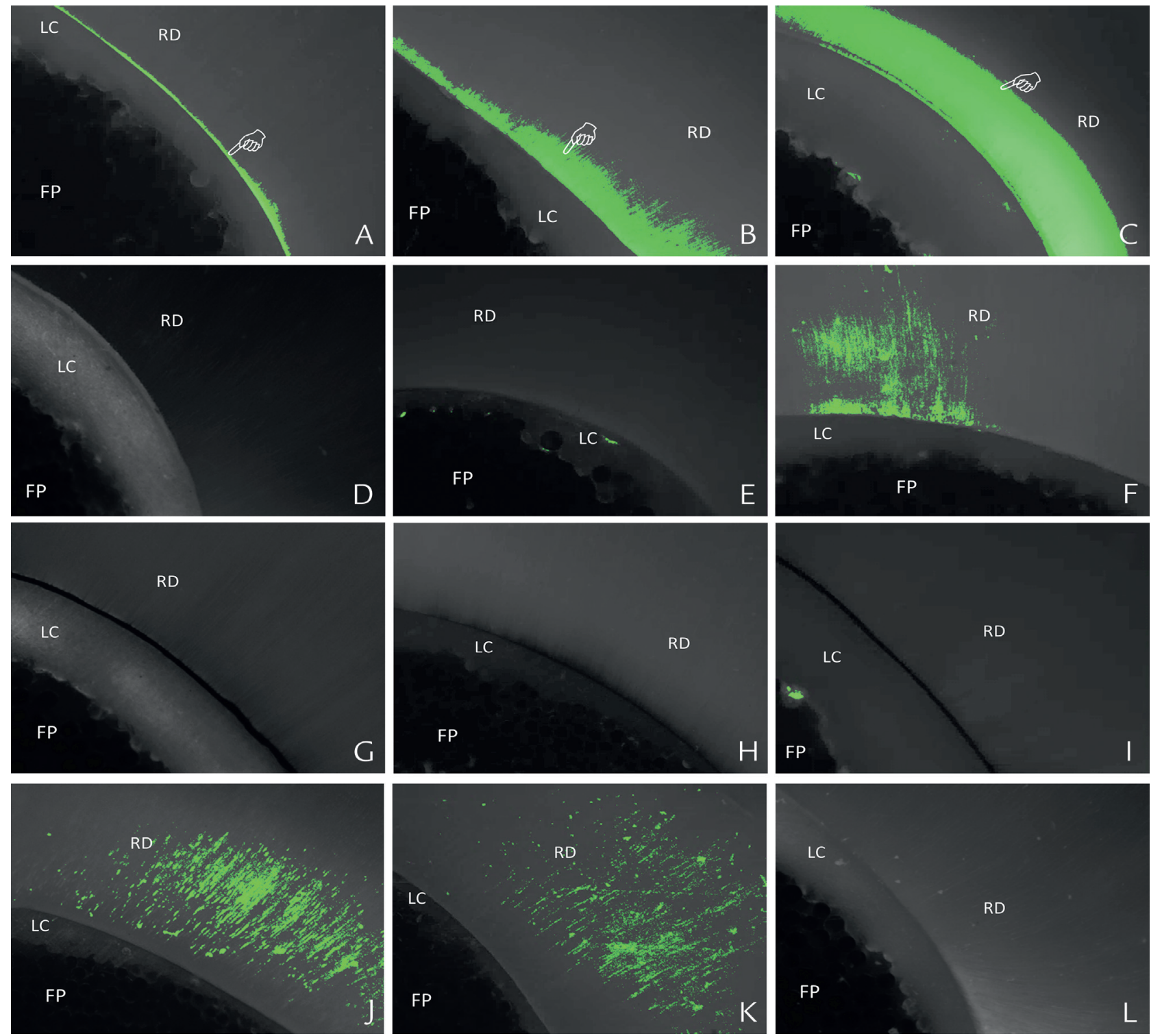

Figure 4. Fluorescence microscope images from 9 months (original magnification, $\times 20$ ). A-C, Intense fluorescence evident in hybrid layers (pointer, bright green) from control group (deionized water), especially for apical third of root canal. Even after 9 months of aging, no fluorescence seen within hybrid layers, irrespective of root canal third. D-F, EDC-treated specimens. G-I, PA-treated specimens. J-L, GD-treated specimens. Fluorescence seen along dentinal tubules corresponds to gelatinolytic activity in lamina limitans. EDC, carbodiimide; FP, fiber post; GD, glutaraldehyde; LC, luting cement; $\mathrm{PA}$, proanthocyanidin; $\mathrm{RD}$, root dentin.

In situ zymography uses fluorescence ${ }^{48}$ to identify active forms of proteolytic enzymes in biological specimens. ${ }^{24}$ These enzymes degrade the gelatinous substrate applied on the specimens, and the fluorescence intensity is directly proportional to the proteolytic activity of the tissue. As a nonspecific test, fluorescence represents the total activity of tissue proteases. For dentin, this means that in situ zymography detects the activity of MMP-1, -2, $-8,-9,-13$, and -20 as well as cysteine catepsins. ${ }^{19-21,49}$

Intense proteolytic activity, which was concentrated in the hybrid layer, was observed for the water-treated specimens (control). This high activity in the hybrid layer region indicated the release and activation of dentin proteases that were not enveloped by the adhesive system because of the acid etching. ${ }^{22}$ Once free, these enzymes degraded the gelatinous substrate from the zymography kit, resulting in the intense fluorescence observed for the control group. Conversely, absence or minimal fluorescence was observed in the groups treated with crosslinkers. These results validate the ability of these crosslinkers to inhibit dentin proteases as reported previously. ${ }^{10,27-32,37-39}$

The inactivation mechanism of MMPs by crosslinkers is related to changes in the catalytic domain of the 
enzyme or to the allosteric inhibition of other domains that participate in the degradation of collagen by modifying the structural conformation of the enzyme. ${ }^{50,51}$ The same stiffness on the collagen due to the increased number of intramolecular, intermolecular, and sinterfibrilar crosslinks induced by the crosslinker ${ }^{22,27}$ also occurs when the dentin enzymes come into contact with these agents. The new crosslinks between amino acids within the catalytic site of the enzymes may irreversibly alter the spatial conformation or flexibility of the cleftlike catalytic domain and prevent its optimal recognition and complexing with the collagen substrate. ${ }^{51,52} \mathrm{~A}$ recent study $^{36}$ demonstrated that the durability of the inhibition of dentin proteases was both crosslinker and dose dependent. According to the same study, the proteolytic inhibitory effect of $5 \%$ PA and GD, as used in the present study, lasts up to 6 months.

Loss of bond strength was seen for the water-treated group (control) after 9 months of storage in artificial saliva. Conversely, the use of crosslinkers decelerated hybrid layer degradation, and bond strengths were similar. However, that positive effect was limited to the cervical third of the root canal (Fig. 1). The third null hypothesis was also partially rejected.

These results should be interpreted with caution because the interfaces were directly exposed to the aging solution and consequently subjected to intense challenge. In the clinical situation, the protective effect exerted by the crosslinkers might be extended beyond the cervical third of the root canal and needs further investigation. Despite the loss of bond strength seen for the middle and apical thirds of the root canal, no fluorescence was detected in the hybrid layer of the crosslinkertreated specimens (Fig. 4).

The results of the present study indicate that the effects promoted by the crosslinkers lasted long enough to protect the collagen against enzymatic degradation. ${ }^{36}$ However, both collagen and resin polymer may still have been subjected to the hydrolytic degradation imposed by the water content within and around the hybrid layer, decreasing the bond strength for the middle and apical thirds of the root canal. Considering the challenging conditions that need to be overcome to create a long-lasting bond to root canal dentin, ${ }^{43,53}$ future studies should investigate the effects of crosslinkers alone or combined with other antidegradation strategies to improve the bond strength and retention of radicular posts.

\section{CONCLUSIONS}

Based on the findings of this in vitro study, the following conclusions were drawn:

1. EDC and GD did not interfere with the immediate bond strength of fiber posts cemented to root canal dentin.
2. After 9 months of aging, all crosslinkers (EDC, GD, and PA) prevented loss of bond strength, but only in the cervical third of the canal.

3. Inhibition of proteolytic activity was seen along the entire fiber post-root canal dentin interface.

\section{REFERENCES}

1. Spencer P, Ye Q, Park J, Topp EM, Misra A, Marangos O, et al. Adhesive/ dentin interface: the weak link in the composite restoration. Ann Biomed Eng 2010;38:1989-2003.

2. Nakabayashi N, Kojima K, Masuhara E. The promotion of adhesion by the infiltration of monomers into tooth substrates. J Biomed Mater Res 1982;16: 265-73.

3. Van Noort R, Norooze S, Howard I, Cardew G. A critique of bond strength measurements. J Dent 1989;17:61-7.

4. Van Noort R, Cardew G, Howard I, Norooze S. The effect of local interfacial geometry on the measurements of the tensile bond strength to dentin. J Dent Res 1991;70:889-93.

5. Reis A, Carrilho M, Breschi L, Loguercio A. Overview of clinical alternatives to minimize the degradation of the resin-dentin bonds. Oper Dent 2013;38:E1-25.

6. Carrilho MR, Tay FR, Donnelly AM, Agee KA, Tjäderhane L, Mazzoni A, et al. Host-derived loss of dentin matrix stiffness associated with solubilization of collagen. J Biomed Mater Res B Appl Biomater 2009;90:373-80.

7. Pashley DH, Tay FR, Yiu C, Hashimoto M, Breschi L, Carvalho RM, et al. Collagen degradation by host-derived enzymes during aging. J Dent Res 2004;83:216-21.

8. Tjäderhane L, Nascimento FD, Breschi L, Mazzoni A, Tersariol IL, Geraldeli S, et al. Strategies to prevent hydrolytic degradation of the hybrid layer-a review. Dent Mater 2013:29:999-1011.

9. De Munck J, Van Meerbeek B, Yoshida Y, Inoue S, Vargas M, Suzuki K, et al Four-year water degradation of total-etch adhesives bonded to dentin. J Dent Res 2003:82:136-40.

10. Mazzoni A, Nascimento FD, Carrilho M, Tersariol I, Papa V, Tjäderhane L, et al. MMP activity in the hybrid layer detected with in situ zymography J Dent Res 2012;91:467-72.

11. Tjäderhane L, Carrilho MR, Breschi L, Tay FR, Pashley DH. Dentin basic structure and composition-an overview. Endodontic Topics 2012;20:3-29.

12. Pashley DH, Tay FR, Breschi L, Tjäderhane L, Carvalho RM, Carrilho M, et al State of the art etch-and-rinse adhesives. Dent Mater 2011:27:1-16.

13. Pashley DH, Tay FR, Carvalho RM, Rueggeberg FA, Agee KA, Carrilho M, et al. From dry bonding to water-wet bonding to ethanol-wet bonding. A review of the interactions between dentin matrix and solvated resins using a macromodel of the hybrid layer. Am J Dent 2007;20:7-21.

14. Kanca J 3rd. Improving bond strength through acid etching of dentin and bonding to wet dentin surfaces. J Am Dent Assoc 1992;123:35-43.

15. Wang $Y$, Spencer P. Hybridization efficiency of the adhesive/dentin interface with wet bonding. J Dent Res 2003;82:141-5.

16. Spencer P, Wang Y, Katz JL. Identification of collagen encapsulation at the dentin/adhesive interface. J Adhes Dent 2004;6:91-5.

17. Jacobsen T, Söderholm KJ. Some effects of water on dentin bonding. Dent Mater 1995;11:132-6.

18. Carvalho RM, Manso AP, Geraldeli S, Tay FR, Pashley DH. Durability of bonds and clinical success of adhesive restorations. Dent Mater 2012;28:72-86.

19. Mazzoni A, Mannello F, Tay FR, Tonti GA, Papa S, Mazzotti G, et al. Zymographicanalysis and characterization of MMP-2 and -9 forms in human sound dentin. J Dent Res 2007:86:436-40.

20. Sulkala M, Tervahartiala T, Sorsa T, Larmas M, Salo T, Tjäderhane L. Matrix metalloproteinase-8 (MMP-8) is the major collagenase in human dentin Arch Oral Biol 2007:52:121-7.

21. Mazzoni A, Papa V, Nato F, Carrilho M, Tjäderhane L, Ruggeri A, et al. Immunohistochemical and biochemical assay of MMP-3 in human dentine. J Dent 2011;39:231-7.

22. Tjäderhane L, Nascimento FD, Breschi L, Mazzoni A, Tersariol ILS, Geraldeli S, et al. Optimizing dentin bond durability: control of collagen degradation by matrix metalloproteinases and cysteine cathepsins. Dent Mater 2013:29:116-35.

23. Kostoryz EL, Dharmala K, Ye Q, Wang Y, Huber J, Park JG, et al. Enzymatic biodegradation of HEMA/bisGMA adhesives formulated with different water content. J Biomed Mater Res B Appl Biomater 2009:88:394-401.

24. Stamenkovic I. Extracelular matriz remodeling: the role of matriz metalloproteinase. J Pathol 2003;200:448-64.

25. Hannas AR, Pereira JC, Granjeiro JM, Tjäderhane L. The role of matrix metalloproteinases in the oral environment. Acta Odontol Scand 2007;65: 1-13.

26. Han B, Jaurequi J, Tang BW, Nimni ME. Proanthocyanidin: a natural crosslinking reagent for stabilizing collagen matrices. J Biomed Mater Res A $2003 ; 65: 118-24$ 
27. Charulatha V, Rajaram A. Influence of different crosslinking treatments on the physical properties of collagen membranes. Biomaterials 2003:24:759-67.

28. Bedran-Russo AK, Pereira PN, Duarte WR, Drummond JL, Yamauchi M. Application of crosslinkers to dentin collagen enhances the ultimate tensile strength. J Biomed Mater Res B Appl Biomater 2007:80:268-72.

29. Bedran-Russo AK, Pashley DH, Agee K, Drummond JL, Miescke KJ. Changes in stiffness of demineralized dentin following application of collagen cross-linkers. J Biomed Mater Res B Appl Biomater 2008;86B:330-4.

30. Al-Ammar A, Drummond JL, Bedran-Russo AK. The use of collagen crosslinking agents to enhance dentin bond strength. J Biomed Mater Res B App. Biomater 2009;91:419-24.

31. Green B, Yao X, Ganguly A, Xu C, Dusevich V, Walker MP, et al. Grape seed proanthocyanidins increase collagen biodegradation resistance in the dentin/ adhesive interface when included in an adhesive. J Dent 2010;38:908-15.

32. Scheffel DL, Hebling I, Scheffel RH, Agee KA, Cadenaro M, Turco G, et al. Stabilization of dentin matrix after cross-linking treatments, in vitro. Dent Mater 2014;30:227-33.

33. Mazzoni A, Angeloni V, Apolonio FM, Scotti N, Tjäderhane L, TezvergilMutluay A, et al. Effect of carbodiimide (EDC) on the bond stability of etchand-rinse adhesive systems. Dent Mater 2013;29:1040-7.

34. Mazzoni A, Apolonio FM, Saboia VP, Santi S, Angeloni V, Checchi V, et al. Carbodiimide inactivation of MMPs and effect on dentin bonding. I Dent Res 2014:93:263-8

35. Castellan CS, Bedran-Russo AK, Antunes A, Pereira PN. Effect of dentin biomodification using naturally derived collagen cross-linkers: one-year bond strength study. Int J Dent 2013;2013:918010.

36. Seseogullari-Dirihan R, Mutluay MM, Pashley DH, Tezvergil-Mutluay A. Is the inactivation of dentin proteases by crosslinkers reversible? Dent Mater 2017;33:e62-8.

37. Epasinghe DJ, Yiu CK, Burrow MF, Hiraishi N, Tay FR. The inhibitory effect of proanthocyanidin on soluble and collagen-bound proteases. J Dent 2013:41:832-9.

38. Scheffel DL, Hebling J, Scheffel RH, Agee K, Turco G, de Souza Costa CA, et al. Inactivation of matrix-bound matrix metalloproteinases by cross-linking agents in acid-etched dentin. Oper Dent 2014:39:152-8.

39. Tezvergil-Mutluay A, Mutluay MM, Agee KA, Seseogullari-Dirihan R, Hoshika T, Cadenaro M, et al. Carbodiimide cross-linking inactivates soluble and matrix-bound MMPs, in vitro. J Dent Res 2012;91:192-6.

40. Shafiei F, Yousefipour B, Bassir MM. Effect of carbodiimide on bonding durability of adhesive-cemented fiber posts in root canals. Oper Dent 2016;41:432-40

41. Cecchin D, Pin LC, Farina AP, Souza M, Vidal Cde M, Bello YD, et al. Bond strength between fiber posts and root dentin treated with natural crosslinkers. J Endod 2015;41:1667-71.

42. Kalra M, Iqbal K, Nitisusanta LI, Daood U, Sum CP, Fawzy AS. The effect of proanthocyanidins on the bond strength and durability of resin sealer to root dentine. Int Endod J 2013;46:169-78.
43. Wagner MH, da Rosa RA, de Figueiredo JA, Duarte MA, Pereira JR, Só MV. Final irrigation protocols may affect intraradicular dentin ultrastructure. Clin Oral Investig 2017;21:2173-82.

44. Santos J, Carrilho M, Tervahartiala T, Sorsa T, Breschi L, Mazzoni A, et al. Determination of matrix metalloproteinases in human radicular dentin. J Endod 2009;35:686-9.

45. Lee TY, Jin EJ, Choi B. MMP-13 Expression in coronal and radicular dentin according to caries progression-a pilot study. Tissue Eng Reg Med 2013;10: 317-21.

46. Inoue T, Saito M, Yamamoto M, Debari K, Kou K, Nishimura F, et al. Comparison of nanohardness between coronal and radicular intertubular dentin. Dent Mater 2009:28:295-300.

47. Scheffel DL, Bianchi L, Soares DG, Basso FG, Sabatini C, de Souza Costa CA, et al. Transdentinal cytotoxicity of carbodiimide (EDC) and glutaraldehyde on odontoblast-like cells. Oper Dent 2015;40:44-54.

48. Polassari $\mathrm{H}$, Pennongton CJ, Lamas MDRE, Tjäderhane L, Salo T. Expression profile of matrix metalloproteinases (MMPs) and tissue inhibitors of MMPs in mature odontoblasts and pulp tissue. Eur Oral J Sci 2003:111:117-27.

49. Sulkala M, Larmas M, Sorsa T, Salo T, Tjäderhane L. The localization of matrix metalloproteinase-20 (MMP-20, enamelysin) in mature human teeth. J Dent Res 2002;81:603-7.

50. Sela-Passwell N, Rosenblum G, Shoham T, Sagi I. Structural and functional bases for allosteric control of MMP activities: can it pave the path for selective inhibition? Biochem Biophys Acta 2010;1803:29-38.

51. Liu Y, Tjäderhane L, Breschi L, Mazzoni A, Li N, Mao J, et al. Limitations in bonding to dentin and experimental strategies to prevent bond degradation. J Dent Res 2011;90:953-68.

52. O'Farrell TJ, Guo R, Hasegawa H, Pourmotabbed T. Matrix metalloproteinase-1 takes advantage of the induced fit mechanism to cleave the triple-helical type I collagen molecule. Biochemistry 2006;45: 15411-8.

53. Bouillaguet S, Troesch S, Wataha JC, Krejci I, Meyer JM, Pashley DH. Microtensile bond strength between adhesive cements and root canal dentin. Dent Mater 2003;19:199-205.

\section{Corresponding author:}

Dr Josimeri Hebling

Department of Orthodontics and Pediatric Dentistry

São Paulo State University (UNESP), School of Dentistry

Rua Humaitá, 1680

Araraquara, São Paulo, 14801-903

BRAZIL

Email: jhebling@foar.unesp.br

Copyright (C) 2017 by the Editorial Council for The Journal of Prosthetic Dentistry. 